\title{
The effect of re-dissolution solvents and HPLC columns on the analysis of mycosporine-like amino acids in the eulittoral macroalgae Prasiola crispa and Porphyra umbilicalis
}

\author{
Ulf Karsten • Karine Escoubeyrou • François Charles
}

Received: 30 September 2008 / Revised: 13 February 2009 / Accepted: 20 February 2009 / Published online: 14 March 2009

(C) Springer-Verlag and AWI 2009

\begin{abstract}
Many macroalgal species that are regularly exposed to high solar radiation such as the eulittoral green alga Prasiola crispa and the red alga Porphyra umbilicalis synthesize and accumulate high concentrations of mycosporine-like amino acids (MAAs) as UV-sunscreen compounds. These substances are typically extracted with a widely used standard protocol following quantification by various high performance liquid chromatography (HPLC) techniques. However, further preparation steps prior to HPLC analysis as well as different HPLC column types have not been systematically checked regarding separation quality and reproducibility. Therefore pure methanol, distilled water and HPLC eluent were evaluated as re-dissolution solvent for dried Prasiola and Porphyra extracts, which were subsequently analyzed on three reversed-phase C8 and C18 HPLC columns. The data indicate that distilled water and the HPLC eluent gave almost identical peak patterns and MAA contents on the $\mathrm{C} 8$ and $\mathrm{C} 18$ columns. In contrast, the application of the widely used methanol led to double peaks or even the loss of specific peaks as well as to a strong decline in total MAA amounts ranging from about $35 \%$ of the maximum in $P$. crispa to $80 \%$ of the maximum in $P$. umbilicalis. Consequently, methanol should be avoided as re-dissolution solvent for the HPLC sample preparation. An improved protocol for the MAA analysis in
\end{abstract}

Communicated by H.-D. Franke.

U. Karsten $(\bowtie)$

Institute of Biological Sciences, University of Rostock,

Albert-Einstein Strasse 3, 18059 Rostock, Germany

e-mail: ulf.karsten@uni-rostock.de

K. Escoubeyrou $\cdot$ F. Charles

CNRS, UMR 7621, LOBB, Observatoire Océanologique,

66651 Banyuls/mer, France macroalgae in combination with a reliable C18 column is suggested.

Keywords Photoprotection - Reversed-phase column · UV-sunscreen

\section{Introduction}

For algae exposed to enhanced ultraviolet radiation (UVR) for substantial parts of their life-cycles, strategies that passively screen this waveband will contribute to prevent UV-induced damage to essential biomolecules such as DNA and proteins (Bischof et al. 2006). In addition, UV-screening may also save metabolic energy by reducing the need for constantly active avoidance and repair processes.

The most common photoprotective sunscreens in many, but not all algal taxa and cyanobacteria are the mycosporine-like amino acids (MAAs), a suite of chemically closely related, colorless, water-soluble, polar and at cellular $\mathrm{pH}$ uncharged or zwitterionic amino acid derivatives. MAAs are related to fungal mycosporines which were first isolated from sporulating mycelia (Leach 1965; Favre-Bonvin et al. 1976), and consist of aminocyclohexenone or aminocyclohexenimine ring systems. The various MAA structures result from $\mathrm{N}$-substitutions of different amino acid moieties to the cyclohexenone or cyclohexenimine chromophore. At present, there are only few known aminocyclohexenonederived MAAs such as mycosporine-glycine, which typically exhibit their absorption maximum in the UVB (280-315 nm, C.I.E. definition) range. All others, about 20 described MAAs are derivaties of the aminocyclohexenimine structure which maximally absorbs at UVA (315-400 nm) wavelengths (Cockell and Knowland 1999; Karentz 2001; Shick and Dunlap 2002). Many algae and cyanobacteria 
contain multiple MAAs, of which some have been identified. However, particularly for cyanobacteria most chemical structures are still to be elucidated (Garcia-Pichel and Castenholz 1993). MAAs were invoked to function as passive shielding solutes by dissipating the absorbed short wavelength radiation energy in the form of harmless heat without generating photochemical reactions (Bandaranayake 1998). These biomolecules exhibit extremely high molar absorptivity for UVA and UVB (molar extinction coefficients between 28.000 and 50.000), and have been reported as photochemically stable structures, both of which are prerequisites for their sunscreen function (Conde et al. 2000).

For qualitative and quantitative analysis of MAAs different HPLC (high performance liquid chromatography) techniques have been applied (Tartarotti and Sommaruga 2002; Caretto et al. 2005 and references therein) with a preference for the widely used method of Dunlap and Chalker (1986). Except the more recent technique of Caretto et al. (2005) all other HPLC methods fail to separate a complex mixture of MAAs from different marine organisms because of the specific physico-chemical properties of individual MAAs. Caretto et al. (2005) coupled two reverse-phase C18-columns with different selectivity for polar compounds and introduced a complex gradient eluent system at low $\mathrm{pH}$. Although this approach is highly suitable for screening of new and unknown MAAs in marine organisms, preparation and analysis are time-consuming and hence are not adequate for routine measurements in organisms with known MAA composition.

The protocols to extract MAAs from biological samples largely differ in the organic solvents used, in the extraction times and temperatures as well as in concomitant cell rupture approaches leading to significant different extraction efficiencies (Tartarotti and Sommaruga 2002). Consequently, these authors compared different protocols and recommended a simple but highly accurate methodological approach for standard MAA extraction. After extraction of MAAs, the extracts are typically evaporated to dryness and, depending on the authors, re-dissolved in different solvents such as aqueous to pure methanol, distilled water or the respective HPLC eluent (Gleason 1993; Dionisio-Sese et al. 1997; Bracher and Wiencke 2000; Caretto et al. 2001, Figueroa et al. 2003). However, to our knowledge the effect of these solvents on the MAA analysis has never been systematically evaluated, particularly not in combination with the widely used reversed-phase C8 and C18 HPLC columns. The motivation of the present study was related to various analytical problems on C8 columns such as suddenly appearing double peaks of standard MAAs, as well as decreasing resolution between the major red algal MAAs shinorine and porphyra-334. Since the standard extraction protocol of Tartarotti and Sommaruga (2002) has always been successfully used with our macroalgal samples (Karsten et al. 1998) the major goal was to evaluate the re-dissolution step and different column types. As model organisms, the green macroalga Prasiola crispa and the red macroalga Porphyra umbilicalis were chosen because as eulittoral organisms they are regularly exposed to high solar radiation and hence synthesize and accumulate MAAs.

\section{Methods}

Macroalgal samples

Specimens of the green macroalga Prasiola crispa (Lightfoot) Kützing were collected during the summer season 2006 from a subaerial rocky cliff. The collection site was located in a distance of $100 \mathrm{~m}$ from the shore and about 2-3 $\mathrm{m}$ above $\mathrm{NN}$ underneath a seagull colony in the inner part of the Kongsfjorden (Ny-Ålesund, Spitsbergen, Norway, $78^{\circ} 55.5^{\prime} \mathrm{N}$, $11^{\circ} 56.0^{\prime} \mathrm{E}$ ). The red macroalga Porphyra umbilicalis (L.) J. Agardh was collected in 2003 from the rocky upper littoral zone at the island Helgoland, North Sea, Germany, $\left(54.2^{\circ} \mathrm{N}\right.$, $7.9^{\circ} \mathrm{E}$ ). All algal samples were collected under air-dried conditions with tweezers and put in black bags to avoid exposure to high irradiance during transportation, followed by short rinsing with tap water in the laboratory to remove sediment and fecal particles. Afterwards, algal thalli were oven-dried at $40^{\circ} \mathrm{C}$ overnight, and stored in sealed plastic bags under dark, dry and cool conditions $\left(4-10^{\circ} \mathrm{C}\right)$ prior analysis. This treatment has no affect on the MAA concentrations, and such samples could be stored for many years without any degradation (unpublished results).

\section{MAA extraction and analysis}

Three replicate macroalgal samples each of about $10 \mathrm{mg}$ dry weight (DW) were extracted for $1.5-2 \mathrm{~h}$ in screwcapped centrifuge vials filled with $1 \mathrm{~mL} 25 \%$ aqueous methanol (v/v) and incubated in a waterbath at $45^{\circ} \mathrm{C}$ (Tartarotti and Sommaruga 2002). After centrifugation at $5,000 \mathrm{~g}$ for $5 \mathrm{~min}, 700 \mu \mathrm{L}$ of the supernatants were evaporated to dryness under vacuum (Speed Vac Concentrator SVC $100 \mathrm{H})$. Figure 1 shows a schematic diagram of the further methodological strategy. Dried extracts were re-dissolved in either $700 \mu \mathrm{L} 100 \%$ methanol, distilled water or the HPLC eluent [2.5\% aqueous methanol (v/v) plus $0.1 \%$ acetic acid $(\mathrm{v} / \mathrm{v})$ in water], and all samples were vortexed for $30 \mathrm{~s}$. After centrifugation at $5,000 \mathrm{~g}$ for $5 \mathrm{~min}$ the extracts were passed through a $0.2 \mu \mathrm{m}$ membrane filter, and afterwards analyzed with an Agilent HPLC system equipped with an autoinjector according to the method of Karsten et al. (1998), modified as follows (Fig. 1). MAAs 


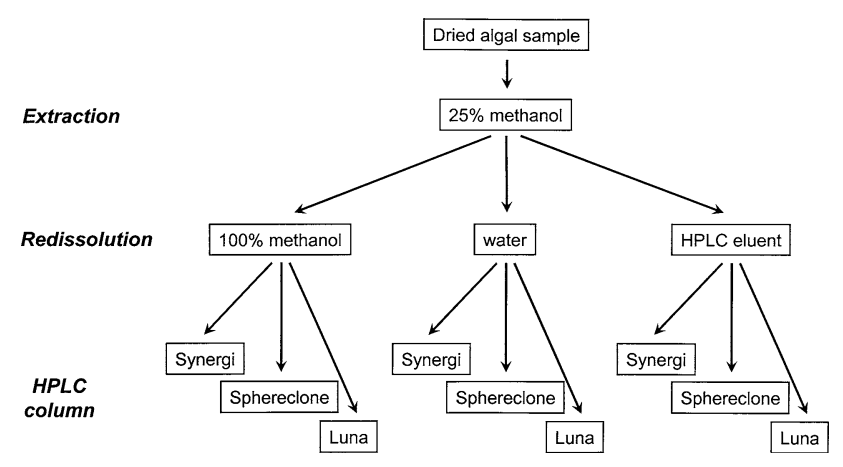

Fig. 1 Methodological protocol with the different re-dissolution solvents and HPLC columns used

in all extracts were one after another separated on three different stainless-steel HPLC columns: (1) Phenomenex Synergi Fusion RP-18 column $(4 \mu \mathrm{m}, 250 \times 3.0 \mathrm{~mm}$ I.D. $)$ protected with a RP-18 guard cartridge $(20 \times 4 \mathrm{~mm} \mathrm{I.D.})$ of the same material, (2) Phenomenex Sphereclone ODS (RP-8) column $(5 \mu \mathrm{m}, 250 \times 4.6 \mathrm{~mm}$ I.D. $)$ protected with a RP-8 guard cartridge $(20 \times 4 \mathrm{~mm}$ I.D.) of the same material, and (3) Phenomenex Luna C8(2) column (5 $\mu \mathrm{m}$, $250 \times 4.6 \mathrm{~mm}$ I.D.) protected with a RP-8 guard cartridge $(20 \times 4 \mathrm{~mm}$ I.D. $)$ of the same material. The mobile phase was always $2.5 \%$ aqueous methanol $(\mathrm{v} / \mathrm{v})$ plus $0.1 \%$ acetic acid (v/v) in water, run isocratically at a flow rate of $0.7 \mathrm{ml} \mathrm{min}^{-1}$ with the Sphereclone column, while both Synergi and Luna columns were run at $0.5 \mathrm{ml} \mathrm{min}^{-1}$. MAAs were detected online with a photodiode array detector at $330 \mathrm{~nm}$, and absorption spectra $(290-400 \mathrm{~nm})$ were recorded each second directly on the HPLC-separated peaks. Identification was done by spectra, retention time and by co-chromatography with pure standards of palythine, porphyra-334 and shinorine kindly sent by Prof. Yabe, Japan. Quantification was made using the molar extinction coefficients given in Karsten et al. (1998).

\section{Statistics}

Mean values of three replicates and standard deviation per treatment were calculated. Statistical significance of differences in the concentrations of total MAA amounts was tested by one-way analysis of variance (ANOVA) followed by a multi-range test using Fisher's protected least significant difference (LSD) according to Sokal and Rohlf (1995). Calculations were done using the program InStat (GraphPad, San Diego, USA).

\section{Results}

Prasiola crispa contained two MAAs with identical absorption spectra and a maximum at $324 \mathrm{~nm}$. Therefore these compounds were described as so-called $324 \mathrm{~nm}$ MAAs (Hoyer et al. 2001) (Table 1). Re-dissolution of dried $P$. crispa extracts in methanol led to much lower signals compared to distilled water or HPLC eluent (Fig. 2). In addition, the latter samples exhibited much sharper peaks while utilization of methanol resulted in double peaks, all with the same absorption maximum. Distilled water and the HPLC eluent gave almost identical chromatograms with all columns. The retention times for both MAAs on the Synergi column with distilled water and HPLC eluent samples were 7.6 and 17.5 min, respectively (Fig. 2, Table 1). The resolution of these MAAs on the C8 Sphereclone column was not as good as on the C18 Synergi column, but with retention times of 3.5 and $4.6 \mathrm{~min}$ still acceptable (Fig. 2). The methanol extract gave three instead of two peaks on the Sphereclone column. In contrast to the Synergi and Sphereclone columns, the Prasiola extracts could not be separated on the C8 Luna column (Fig. 2). Although some small peaks appeared in the chromatograms, the respective absorbance spectra indicated for each peak a mix of unidentifiable compounds. A calculation of the total MAA concentration in $P$. crispa showed strong differences for the re-dissolution solvent and column used. All distilled water and HPLC eluent samples gave with the Synergi and Sphereclone columns similar MAA contents between 5.6 and $6.1 \mathrm{mg} \mathrm{g}^{-1}$ dry weight (Table 1). In contrast, in the methanol samples significantly less MAAs $(2.0-2.1 \mathrm{mg}$ MAAs $\mathrm{g}^{-1}$ dry weight; $P<0.001$ ) were measured, indicating that utilization of methanol as solvent may lead to a strong underestimation of these green algal MAAs.

Porphyra umbilicalis extracts exhibited three main MAAs which could be identified as palythine, shinorine and porphyra-334, as well as some minor unidentifiable compounds (Fig. 3, Table 2). Quantitatively dominating in all samples was always porphyra-334. Re-dissolution of dried $P$. umbilicalis extracts in distilled water or HPLC eluent led on all columns to much higher signals compared to methanol (Fig. 3). In addition, the methanol samples showed broader or even double peaks while utilization of distilled water and HPLC eluent resulted in sharp and symmetric peaks. The retention times for palythine, shinorine and porphyra-334 on the Synergi column with extracts redissolved in distilled water and HPLC eluent were 2.9, 5.4 and $7.7 \mathrm{~min}$, respectively (Fig. 3, Table 2). In contrast with the Sphereclone column, the elution order of these MAAs and extracts changed: shinorine (3.1 min), porphyra-334 ( $3.8 \mathrm{~min}$ ) and palythine $(5.0 \mathrm{~min})$. Compared to the Prasiola extracts the Porphyra samples could be separated on the Luna column (Fig. 3, Table 2). However, while shinorine and porphyra-334 could be easily quantified, palythine did not appear on the chromatograms. In addition, the porphyra-334 peak showed shoulders or some tailing on the Luna column. The calculated total MAA concentrations of 
Table 1 MAA separation and concentrations in extracts of the green alga Prasiola crispa after re-dissolution in different solvents and after using different HPLC columns

\begin{tabular}{|c|c|c|c|c|c|c|}
\hline \multirow[b]{2}{*}{ Column } & \multicolumn{6}{|c|}{ Concentration $\left(\mathrm{mg} \mathrm{g}^{-1} \mathrm{DW}\right)$} \\
\hline & Solvent & MAA-1 (324 nm) & MAA-2 (324 nm) & MAA-3 (324 nm) & MAA-4 (324 nm) & Total \\
\hline Synergi C18 & Methanol & $1.22 \pm 0.1(7.7 \mathrm{~min})$ & $0.64 \pm 0.07(17.2 \mathrm{~min})$ & $\begin{array}{l}0.14 \pm 0.01 \\
\quad(17.5 \mathrm{~min})\end{array}$ & $0.12 \pm 0.02$ & $2.12 \pm 0.19$ \\
\hline Synergi C18 & Water & ND & $4.91 \pm 0.12(7.6 \mathrm{~min})$ & ND & $0.77 \pm 0.02(17.5 \mathrm{~min})$ & $5.68 \pm 0.14$ \\
\hline Synergi C18 & HPLC eluent & ND & $4.87 \pm 0.12(7.6 \mathrm{~min})$ & ND & $1.05 \pm 0.25(17.5 \mathrm{~min})$ & $5.92 \pm 0.21$ \\
\hline Sphereclone C8 & Methanol & $1.84 \pm 0.16(3.4 \mathrm{~min})$ & $0.06 \pm 0.01(4.4 \mathrm{~min})$ & $\begin{array}{r}0.14 \pm 0.01 \\
\quad(4.9 \mathrm{~min})\end{array}$ & ND & $2.04 \pm 0.18$ \\
\hline Sphereclone C8 & Water & $4.70 \pm 0.14(3.5 \mathrm{~min})$ & $0.90 \pm 0.04(4.6 \mathrm{~min})$ & ND & ND & $5.6 \pm 0.21$ \\
\hline Sphereclone C8 & HPLC eluent & $4.85 \pm 0.32(3.5 \mathrm{~min})$ & $1.27 \pm 0.26(4.6 \mathrm{~min})$ & ND & ND & $6.12 \pm 0.17$ \\
\hline Luna C8 & Methanol & a & & & & $<0.5$ \\
\hline Luna C8 & Water & a & & & & $<0.5$ \\
\hline Luna C8 & HPLC eluent & a & & & & $<0.5$ \\
\hline
\end{tabular}

The absorbance maxima of the different MAAs and the retention time in minutes of the respective peaks is given in brackets. Data given represent mean value $\pm \mathrm{SD}(n=3)$. $N D$ not detected

${ }^{\text {a }}$ Mixed unidentifiable peaks

the methanol extracts were significantly $18-37 \%$ lower for all columns compared to the distilled water extracts (Table 2; $P<0.0001$ ). While use of Synergi and Sphereclone columns led to identical total MAA concentrations in Porphyra ranging from 7.88 to $8.01 \mathrm{mg} \mathrm{g}^{-1}$ dry weight in extracts re-dissolved in distilled water and HPLC eluent, the water extract on the Luna column gave c. $40 \%$ higher MAA amounts than the HPLC eluent extract (Table 2). As already mentioned with the Prasiola extracts, the methanol samples of Porphyra gave also much lower total MAA
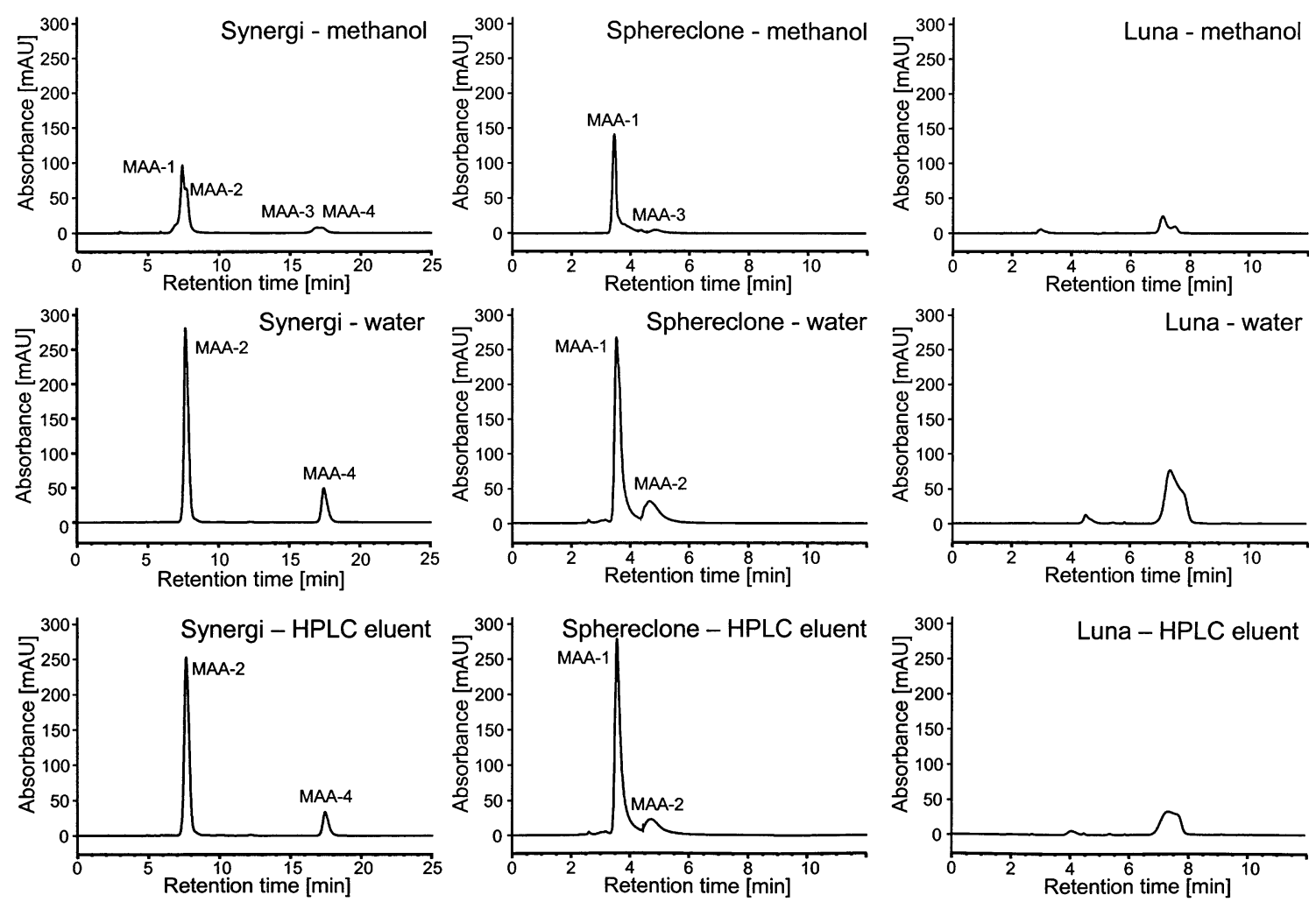

Fig. 2 Representative HPLC chromatograms of MAA extracts from the green macroalgal species Prasiola crispa. The evaporated extracts were re-dissolved in either pure methanol, distilled water or the HPLC eluent, analyzed on different reversed-phase columns and individual peaks detected at $330 \mathrm{~nm}$. Retention time, maximum absorbance and identification of individual peaks are summarized in Table 1 

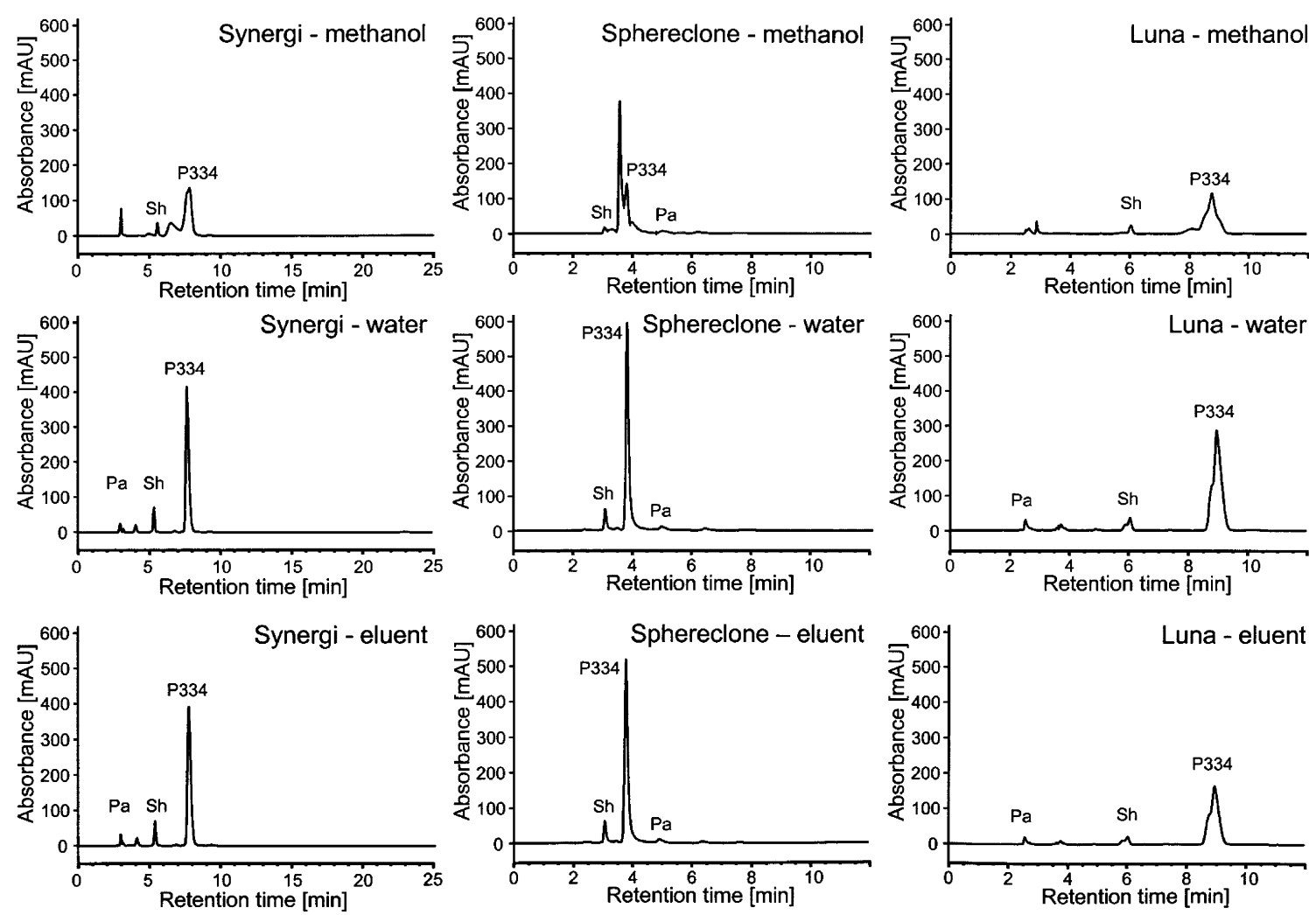

Fig. 3 Representative HPLC chromatograms of MAA extracts from the red macroalgal species Porphyra umbilicalis. The evaporated extracts were re-dissolved in either pure methanol, distilled water or HPLC eluent, analyzed on different reversed-phase columns and individual peaks detected at $330 \mathrm{~nm}$. Retention time, maximum absorbance and identification of individual peaks are summarized in Table 2. $P a$ palythine, $S h$ shinorine, $P 334$ porphyra-334

(data not shown). In addition, utilization of methanol was accompanied by the formation of double peaks such as for porphyra-334 on the Sphereclone column, the loss of specific MAAs such as palythine on the Synergi column and a decrease in total MAA amounts ranging from about $35 \%$ of the maximum in $P$. crispa to $80 \%$ of the maximum in $P$. umbilicalis. The variability in peak areas and/or peak tailing when extracts were re-dissolved in methanol may result from an incompatibility between sample liquid phase and column properties as well as from the much lower solvent concentration of the HPLC eluent. If the chromatographic elution strength of the solvent is much higher compared to the mobile phase this may result in lower plate numbers and hence lower separation efficiency (Sadek 2002). Consequently, methanol should be avoided as redissolution solvent during the sample preparation protocol prior HPLC analysis. Since many scientists used methanol as re-dissolution solvent the respective MAA concentrations published should be taken with great caution because they seem to be underestimated (Table 3).

The results indicate also that MAAs exhibit different physico-chemical properties, which may strongly influence their chromatographic behavior on various reversed-phase anol and much higher variance between replicate injections 


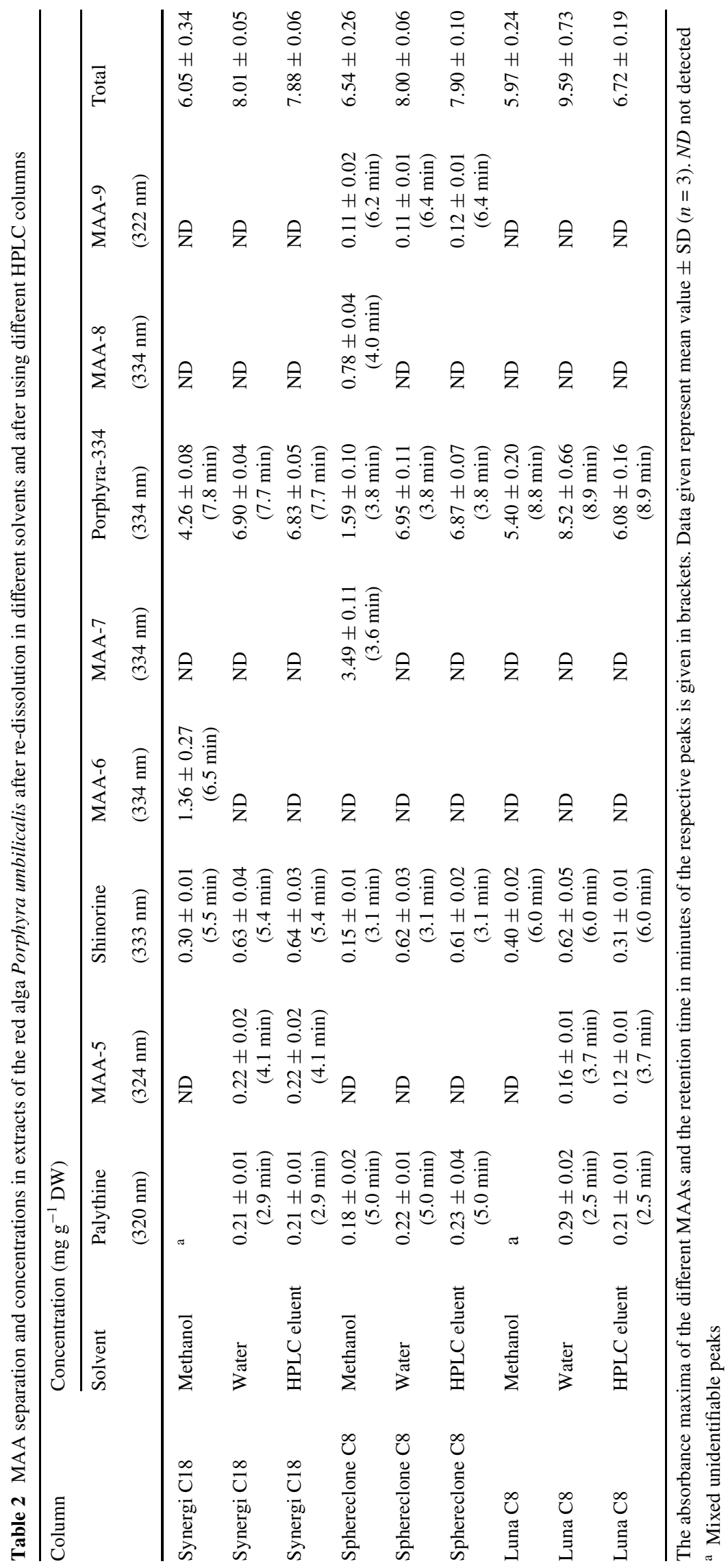


Table 3 The analytical HPLC set-ups available from the literature for the separation of MAAs with an emphasis on the re-dissolution solvents used

\begin{tabular}{|c|c|c|c|}
\hline Re-dissolution solvent & Elution/column & Mobile phase & Reference \\
\hline $100 \%$ methanol & Isocratic/C8 & $0.1 \%$ acetic acid; $25 \%$ aqueous methanol & $\begin{array}{l}\text { Dunlap and Chalker (1986), } \\
\text { Banaszak et al. (2006) }\end{array}$ \\
\hline $100 \%$ methanol & Isocratic/C8 & $0.1 \%$ acetic acid; $25 \%$ aqueous methanol & $\begin{array}{l}\text { Neale et al. (1988), } \\
\text { Karsten et al. (1998) }\end{array}$ \\
\hline $100 \%$ methanol & Isocratic/C8 & $0.1 \%$ acetic acid; $80 \%$ aqueous methanol & Moisan and Mitchell (2001) \\
\hline $100 \%$ methanol & Isocratic/C8 & $0.1 \%$ acetic acid; $5 \%$ aqueous methanol & Figueroa et al. (2003) \\
\hline $100 \%$ methanol & Isocratic/C8 & $0.1 \%$ acetic acid; $2.5 \%$ aqueous methanol & $\begin{array}{l}\text { Korbee et al. (2005), } \\
\text { Karsten et al. (2005), } \\
\text { de la Coba et al. (2008) }\end{array}$ \\
\hline $80 \%$ methanol & Isocratic/C8 & $0.1 \%$ acetic acid; $55 \%$ aqueous methanol & Carroll and Shick (1996) \\
\hline $25 \%$ methanol & Isocratic/C8 & $0.1 \%$ acetic acid; $25 \%$ aqueous methanol & Tartarotti and Sommaruga (2002) \\
\hline Deionized water & Isocratic/C8 & $0.1 \%$ acetic acid; $25 \%$ aqueous methanol & Shick et al. (1999) \\
\hline 80:20 methanol:THF & Gradient/C18 & $\begin{array}{l}\text { From } 0.2 \% \text { acetic acid to } 0.1 \% \text { acetic acid; } \\
25 \% \text { aqueous methanol }\end{array}$ & Dionisio-Sese et al. (1997) \\
\hline $100 \%$ water & Gradient/C18 & $\begin{array}{l}\text { From } 0.2 \% \text { acetic acid to } 0.1 \% \text { acetic acid; } \\
25 \% \text { methanol; } 25 \% \text { acetonitrile }\end{array}$ & Caretto et al. (2001) \\
\hline $\begin{array}{l}0.2 \% \text { aqueous trifluoroacetic } \\
\text { acid/ammonium acetate }\end{array}$ & $\begin{array}{l}\text { Gradient/two } \\
\text { coupled C18 } \\
\text { columns }\end{array}$ & $\begin{array}{l}\text { From } 0.2 \% \text { trifluoroacetic acid/ammonium } \\
\text { hydroxide in water to } 0.2 \% \text { trifluoro-acetic } \\
\text { acid/ammonium hydroxide in water:methanol; } \\
\text { acetonitrile }(80: 10: 10)\end{array}$ & Caretto et al. (2005) \\
\hline
\end{tabular}

columns as extensively discussed in Caretto et al. (2005). While the typical $324 \mathrm{~nm}$-MAAs in $P$. crispa did not give any clear peak on the $\mathrm{C} 8 \mathrm{Luna}$ column independent on the re-dissolution solvent used, the MAAs shinorine and porphyra-334 from $P$. umbilicalis were easy to identify with all 3 solvents applied on this column. The chemical structure and features of palythine, shinorine and porphyra-334 are known for many decades (Bandaranayake 1998, and references therein). Although the $324 \mathrm{~nm}-\mathrm{MAA}$ has been described from various taxa of the subaerial green macroalgal genus Prasiola (Hoyer et al. 2001; Gröniger and Häder 2002), as well as from other closely related subaerial green microalgae of the Trebouxiophyceae colonising building facades (Karsten et al. 2005), the chemical structure is still to be elucidated. However, various preliminary experiments with partially purified extracts and the application of mass spectroscopy indicate the typical aminocyclohexenimine ring system linked to an unknown sugar moiety (data not shown). To our knowledge only one scientific publication on the occurrence of a MAA with a covalently linked oligosaccharide exists which is located in the extracellular glycan of the terrestrial cyanobacterium Nostoc commune (Böhm et al. 1995). It is reasonable to assume that such a chemical modification will strongly influence the chromatographic behavior of the $324 \mathrm{~nm}$-MAAs on the Luna column.

The first author was using for more than a decade reversed-phase C8 columns of different manufactures including the Sphereclone for MAA analysis (e.g. Karsten et al. 1998), and the general experience is a gradual loss in resolution after several hundreds of injections. Although according to the manufacturer's recommendation various regeneration and cleaning procedures for these columns such as rinsing with different solvents at low and high temperatures had been tested, none of the protocols was successful. It seems that unknown contaminations irreversibly bind to the stationary phase which reduce the separation capacity. Consequently, the rate of column replacement and hence concomitant cost was very high for routine MAA analysis.

In contrast, the experience with the C18 Synergi column indicate long-term reproducibility in the separation of MAAs also after more than 2.000 analysis. Besides the separation of palythine $(2.9 \mathrm{~min})$, shinorine $(5.4 \mathrm{~min}$ ) and porphyra-334 (7.7 $\mathrm{min})$, also standards of asterina-330 (3.3 $\mathrm{min})$ and mycosporine-glycine $(4.6 \mathrm{~min})$ can be well separated on this column (data not shown). These five MAAs represent the most abundant UV-absorbing compounds in red algae (Karsten et al. 1998).

While a general methodological approach for the re-dissolution of dried macroalgal MAA extracts and specific reversed-phase HPLC columns does not exist, the data presented clearly indicate that the widely used pure methanol as well as C8 columns may lead to analytical problems. Therefore, re-dissolution in distilled water or in HPLC eluent is recommended in combination with the $\mathrm{C} 18$ Synergi column. Following this technique guarantees separation and routine analysis of the most abundant MAAs in macroalgae. 
Whether this method is also applicable for specific MAAs from marine animals has to be tested in further studies. For analyzing complex MAA mixtures the HPLC gradient method of Caretto et al. (2005) should be used.

Acknowledgments The authors gratefully appreciate excellent technical support by Sebastian Lembcke as well as financial support through the Deutsche Forschungsgemeinschaft (Ka 899/13-1/2).

\section{References}

Banaszak AT, Guadalupe M, Santos B, LaJeunesse TC, Lesser MP (2006) The distribution of mycosporine-like amino acids (MAAs) and the phylogenetic identity of symbiotic dinoflagellates in cnidarian hosts from the Mexican Caribbean. J Exp Mar Biol Ecol 337:131-146

Bandaranayake WM (1998) Mycosporines: are they nature's sunscreens? Nat Prod Rep 15:159-172

Bischof K, Gómez I, Molis M, Hanelt D, Karsten U, Lüder U, Roleda MY, Zacher K, Wiencke C (2006) Ultraviolet radiation shapes seaweed communities. Rev Environ Sci Biotech 5:141-166

Böhm GA, Pfleiderer W, Böger P, Scherer S (1995) Structure of a novel oligosaccharide-mycosporine-amino acid ultraviolet A/B sunscreen pigment from the terrestrial cyanobacterium Nostoc commune. J Biol Chem 270:8536-8539

Bracher UB, Wiencke C (2000) Simulation of the effects of naturally enhanced UV radiation on photosynthesis of Antarctic phytoplankton. Mar Ecol Prog Ser 196:127-141

Caretto JI, Carignan MO, Montoya NG (2001) Comparative studies on mycosporine-like amino acids, paralytic shellfish toxins and pigment profiles of the toxic dinoflagellates Alexandrium tamarense, A. catenella and A. minutum. Mar Ecol Prog Ser 223:49-60

Caretto JI, Carignan MO, Montoya NG (2005) A high-resolution reverse-phase liquid chromatography method for the analysis of mycosporine-like amino acids (MAAs) in marine organisms. Mar Biol 146:237-252

Carroll AK, Shick JM (1996) Dietary accumulation of UV-absorbing mycosporine-like amino acids (MAAs) by the green sea urchin (Stronglocentrotus droebachiensis). Mar Biol 24:561-569

Cockell CS, Knowland J (1999) Ultraviolet radiation screening compounds. Biol Rev 74:311-345

Conde FR, Churio MS, Previtali CM (2000) The photoprotector mechanism of mycosporine-like amino acids. Excited-state properties and photostability of porphyra-334 in aqueous solution. J Photochem Photobiol 56B:139-144

De la Coba F, Aguilera J, Figueroa FL, de Galvez MV, Herrera E (2008) Antioxidant activity of mycosporine-like amino acids isolated from three red macroalgae and one marine lichen. J Appl Phycol. doi:10.1007/s10811-008-9345-1

Dionisio-Sese ML, Ishikura M, Maruyama T, Miyachi S (1997) UVabsorbing substances in the tunic of a colonial ascidian protect its symbiont. Prochloron sp., from damage by UV-B radiation. Mar Biol 128:455-461

Dunlap WC, Chalker BE (1986) Identification and quantification of near-UV absorbing compounds (S-320) in a hermatypic scleratinian. Coral Reefs 5:155-159
Favre-Bonvin J, Arpin N, Brevard C (1976) Structure de la mycosporine. Can J Chem 54:1105-1113

Figueroa FL, Escassi L, Pérez-Rodríguez E, Korbee N, Giles AD, Johnsen G (2003) Effects of short-term irradiation on photoinhibition and accumulation of mycosporine-like amino acids in sun and shade species of the red algal genus Porphyra. J Photochem Photobiol B: Biol 69:21-30

Garcia-Pichel F, Castenholz RW (1993) Occurrence of UV-absorbing, mycosporine-like compounds among cyanobacterial isolates and an estimate of their screening capacity. Appl Environ Microb $59: 163-169$

Gleason DF (1993) Differential effects of ultraviolet radiation on green and brown morphs of the Caribbean coral Porites astreoides. Limnol Oceanogr 38:1452-1463

Gröniger A, Häder DP (2002) Induction of the synthesis of an UV-absorbing substance in the green alga Prasiola stipitata. J Photochem Photobiol B Biol 66:54-59

Hoyer K, Karsten U, Sawall T, Wiencke C (2001) Photoprotective substances in Antarctic macroalgae and their variation with respect to depth distribution, different tissues and developmental stages. Mar Ecol Prog Ser 211:117-129

Karentz D (2001) Chemical defenses of marine organisms against solar radiation exposure: UV absorbing mycosporine-like amino acids and scytonemin. In: McClintock JB, Baker BJ (eds) Marine chemical ecology. CRC Press, Boca Raton, pp 481-519

Karsten U, Sawall T, Wiencke C (1998) A survey of the distribution of UV-absorbing substances in tropical macroalgae. Phycol Res 46:271-279

Karsten U, Friedl T, Schumann R, Hoyer K, Lembcke S (2005) Mycosporine like amino acids (MAAs) and phylogenies in green algae: Prasiola and its relatives from the Trebouxiophyceae (Chlorophyta). J Phycol 41:557-566

Korbee N, Huovinen P, Figueroa FL, Aguilera J, Karsten U (2005) Availability of ammonium influences photosynthesis and the accumulation of MAAs in two Porphyra species (Bangiales, Rhodophyta). Mar Biol 146:645-654

Leach CM (1965) Ultraviolet absorbing substances associated with light-induced sporulation in fungi. Can J Bot 43:185-200

Moisan TA, Mitchell BG (2001) UV absorption by mycosporine-like amino acids in Phaeocystis antarctica Karsten induced by photosynthetically available radiation. Mar Biol 138:217-227

Neale PJ, Banaszak AT, Jarriel CR (1988) Ultraviolet sunscreens in Gymnodinium sanguineum (Dinophyceae): mycosporine-like amino acids protect against inhibition of photosynthesis. J Phycol 34:928-938

Sadek PC (2002) The HPLC solvent guide. Wiley, New York

Shick JM, Dunlap WC (2002) Mycosporine-like amino acids and related gadusols: biosynthesis, accumulation, and UV-protective functions in aquatic organisms. Ann Rev Physiol 64:223-262

Shick JM, Romaine-Lioud S, Ferrier-Pages C, Gattuso JP (1999) Ultraviolet-B radiation stimulates shikimate pathway-dependent accumulation of mycosporine-like amino acids in the coral Stylophora pistillata despite decreases in its population of symbiotic dinoflagellates. Limnol Oceanogr 44:1667-1682

Sokal RR, Rohlf FJ (1995) Biometry, 3rd edn. Freeman, New York

Tartarotti B, Sommaruga R (2002) The effect of different methanol concentrations and temperatures on the extraction of mycosporine-like amino acids (MAAs) in algae and zooplankton. Arch Hydrobiol 154:691-703 